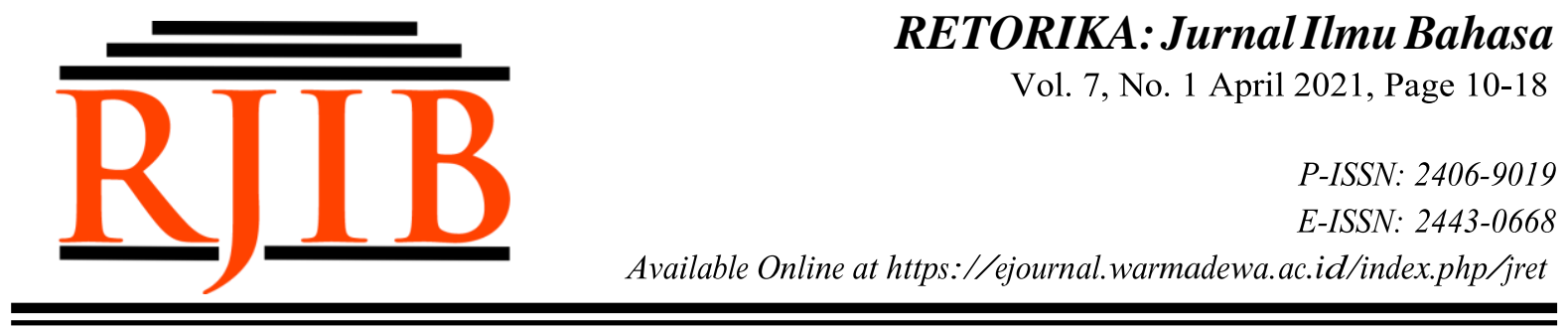

\title{
Schemes of Scaffolding in Online Education
}

\author{
Ni Putu Dewi Ersani ${ }^{1}$, Ni Komang Arie Suwastini ${ }^{2 *}$, Ni Nyoman Padmadewi ${ }^{3}$, Luh Putu Artini ${ }^{4}$ \\ ${ }^{1,2,3,4}$ English Language Education, Post-graduate Program, Universitas Pendidikan Ganesha \\ "Corresponding Author: arie.suwastini@undiksha.ac.id
}

\begin{abstract}
Scaffolding in learning has been argued to facilitate the students' progress. As the educational paradigm inevitably shifts into online modes, strategies for scaffolding provision need to be adjusted. This study aimed to understand the nature of the online learning environment and explore the aspects, types, and methods of scaffolding provision in online learning contexts by adopting George's (2008) research method into a qualitative design. The data were collected from experts' opinions and previous studies, as published in reputable international journals, using Education Resources Information Center (https://eric.ed.gov/), Google Scholar (https://scholar.google.com), and Research Gate (https://www.researchgate.net) as the databases. The research result is presented in an informal method. The review reveals that critical aspects of scaffolding are contingency, fading, and transfer of responsibility, which are applicable in synchronous and asynchronous learning with the support provided by peers, teachers, or technology through static or dynamic interaction. Based on its purpose, the four types of scaffolding are procedural, conceptual, metacognitive, and strategic, which can be performed strategically in online contexts through orientation to the course structure, access to resource and tools, critical thinking development, guidance to problem-solving, provisions of hints, sufficient examples, probing questions, and providing constructive feedback. These findings imply the importance of implementing scaffolding strategies in online learning contexts, although further studies need to be conducted to provide more comprehensive scaffolding models.
\end{abstract}

Keywords: Online learning environment, Online Scaffolding, Scaffolding strategies, Types of Scaffolding in online learning

\section{INTRODUCTION}

Technology is inevitable in this digital era, where every aspect of human life is affected, including education and how students learn (Trilling \& Fadel, 2009; Suwastini, Dantes, Jayanta \& Suprihatin, 2020). With the advance of information/communication technology, learning has shifted from the conventional faceto-face mode into online learning (Todo \& Budiarta, 2018). As proposed by Harasim (2000), online education is a teaching and learning process with networking as a medium. Current trends show that online education has become increasingly popular due to its viability in learning participants' lifestyles, interests, and time (Albrahim, 2020; Harasim, 2000; Utami et al., 2021). This condition results in the increasing demand for capable online instructors and high-quality online courses (Motte, 2013; Marti, Dewi \& Dantes, 2014). The shift of paradigm from face to face meeting to online learning requires adjustment both for the instructors and students (Albrahim, 2020; Motte, 2013; Puspitasari, et al., 2021; Dantes, et al., 2017; Dantes, et al., 2019).

While some aspects of the traditional 
classroom are missing from online classes, the essence of teaching and learning does not shift much. Despite the learning mode, teachers (instructors) have a role in guiding students to acquire new knowledge and skills. In other words, instructors must help students move from their current state of ability to the new state of ability. The zone in which students can do with help and what they can do independently is what Vygotsky (1986) refers to as the Zone of Proximal Development (ZPD). In order to help students pass their Zone of Proximal Development, the instructor's presence and support are much needed. Wood, Bruner \& Ross (1976) explains these supportive behaviors as scaffolding. Support can be given strategically to help a learner achieve higher levels of regulation. It is known as the scaffolding strategy. It is easier for instructors to directly spot problems faced by students in a traditional classroom and give the scaffolding needed. However, online learning requires specific scaffolding strategies so that lesson objectives can be attained well (Schutt, 2003; Dantes, et al., 2019).

Due to its importance, scaffolding has been a widely investigated subject, either as performed by teachers in face-to-face classes (Van de Pol, Volman, \& Beishuizen, 2010) or with the enhancement of technology in face-toface, blended, and online classes (Belland, Walker, Kim, \& Lefler, 2017; Dantes, et el., 2019). With the growing need for high-quality online courses, teachers need to understand the nature of the online learning environment so that providing online scaffolding can be optimized. Thus, a well-structured online course can be designed and delivered to improve the quality of online education. Therefore, this study aimed to understand the nature of the online learning environment and explore the aspects, types, and methods of scaffolding provision in the online learning context through a review of related literature. Teachers may find this article helpful in suggesting ways to implement scaffolding strategies in their online classrooms.

\section{METHODS}

As a preliminary study aimed at providing elaborations on the aspects, types, and strategies of scaffolding, the present study adopted George's model of library research (2008). The sources of data for answering the purpose of the present study were selected from several databases, namely Education Resources Information Center (https://eric.ed.gov/), Google Scholar (https://scholar.google.com), and Research Gate (https://www.researchgate.net). The articles included as the source were (a) written in English, (b) referring to Vygotsky $(1978,1986)$ and Wood et al. (1976), (c) containing the keywords online learning environment, scaffolding strategies, online scaffolding, technology-enhanced scaffolding, scaffolding in online learning, online learning scaffolding strategies, online scaffolding education (d) published in Scopus Indexed Journals, and (e) open-access. There were 40 articles selected through this inclusion/exclusion process.

The articles were then closely read concerning the relevance of their arguments to support the arguments posed by this study. A table of the summary was employed to record the articles and their respective arguments, from which synthesis of similar arguments and mapping of different opinions can be conducted. These processes allow the drawing of insights about the nature, aspects, and strategies of implementing scaffolding in synchronous and asynchronous contexts. The thesis and outline were then drafted, resulting in a report presented in the present article.

\section{RESULT AND DISCUSSION}

This library study resulted in 40 Scopus indexed articles which included nineteen articles in Quartile 1, thirteen articles in Quartile 2, six articles in Quartile 3, and two articles in Quartile 4. The review reveals that most online scaffolding theories refer to the Open Learning Environment framework (Hannafin, Land, \& Oliver, 1999). The findings were further elaborated into the key aspects of scaffolding, the nature of the online learning environment, types of online scaffolding, and how they are implemented in the online classroom.

\section{Scaffolding and Zone of Proximal Development}

The term scaffolding refers to the conditional support given by more capable individuals to a novice learner, especially in the early stage of learning (Wood, Bruner, \& Ross, 1976). The theory of scaffolding is constructed after Vygotsky's (1978) Social Development Theory which includes social interaction, the More Knowledgeable Others (MKO), and Zone of Proximal Development (ZPD). The concept of $Z P D$ refers to three learning points, namely what 
a child cannot do, what he/she can do with support, and what he/she can do independently (Vygotsky, 1978). The area in which a child can do with support is known as ZPD. Further, Vygotsky elaborates three critical components to help a child moving through the zone of proximal development: (1) the attendance of more capable individual, (2) social interaction and feedback from more capable individual, (3) supportive activities (Scaffolding) performed by the more capable individual. In line with Vygotsky, Wood, Bruner, and Ross (1976) propose the importance of social interactions in fostering children's development. Scaffolding as supportive interaction is characterized by its contingency, intersubjectivity, and transfer of responsibility. Scaffolding contingency requires the teacher to give the right amount and type of support based on students' needs. Intersubjectivity helps students recognize their success at mastering a new task or solving a problem. When students are finally able to do a particular task without assistance, a transfer of responsibility occurs. Support is gradually removed since students can already pass their Zone of Proximal Development.

Social interaction and supportive activities can also be provided through peer interaction, which Vygotsky (1978) defines ZPD as "the distance between the actual developmental level as determined by independent problem solving and the level of potential development as determined through problem-solving under adult guidance or in collaboration with more peers". Peer collaboration has been proven to be mutually beneficial to help students reach the new level of capability (De Guerrero \& Villamil, 2000; Hanjani, 2019; Ozan, 2013; Ranjbar \& Ghonsooly, 2017). However, Foley \& Marr (2019) point out that learning through peer collaboration becomes the most effective when being guided by teaching attendance (teacher, instructor) and supported with cognitive attendance (media for applying ideas). How aspects of scaffolding encourage learners' autonomy is visualized by Van de pol et al. (2010) as follows:

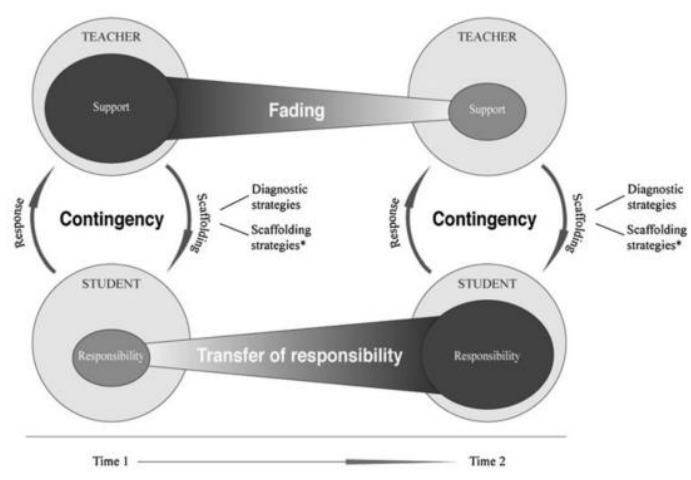

Fig. 1 Conceptual model of scaffolding as proposed by (Van de Pol et al., 2010)

Figure 1 describes the support given by the source of scaffolds (teacher and/or peer) is gradually fading over time. On the other hand, students' autonomy in learning (responsibility) is expected to increase. In order to achieve this condition (low support, high responsibility) teachers should be able to diagnose students' needs and employ the right amount and type of scaffolding (contingency). Once a learner recognizes the new ability they gain, the scaffold can finally be removed. Thus, it can be summarized that conditional support provided strategically through social interaction helps students reach new task mastery.

\section{Types of Scaffolding in Online Learning}

Online learning is not a novel concept in education. It was rooted in distance education in the 1980s and continued to grow in the 1990s and the invention of the World Wide Web (Anderson \& Garrison, 2003; Hannafin et al., 1999; Harasim, 2000). Along with the growth of technology, online education has been blooming and slowly creating the paradigmatic shift to the educational system worldwide (Schutt, 2003). The inevitable shift to online learning is mainly due to its' compatibility with the current lifestyle, in which learners have the flexibility to choose what to learn when to learn, and whom to learn with (Garrison and Anderson, 2003). In addition, Albrahim (2020) argues that online learning opens chances for those with socioeconomic, academic, or health problems to access education.

However, despite the benefits it offers, online learning also has its downsides. In a traditional classroom, students can rely directly on teachers' guidance, seek help from the teacher whenever they face challenges in learning, and confirm their comprehension through real-time discussion. In online learning context, Hannafin 
et al., (1999); Ribbe \& Bezanilla (2013) point out that the success relies greatly on students' autonomy. Holec (1981, as stated in Ribbe \& Bezanilla (2013), defines learner's autonomy as one's responsibility for his/her learning, which includes choosing their own learning goals, methods and materials, and reflecting on their learning achievement. To support this, Bautista (2013) argues that "online learning happens in a community of inquiry in a self-regulated constructive learning environment." These two ideas are interrelated: online learning flexibility and students' autonomy. In order to foster students' learning autonomy, specified scaffolding strategies should be integrated into online classes.

The notion of technology-enhanced scaffolding was first proposed by Hannafin (1989), as stated in Garrison and Anderson (2011), which includes five interactive functions of technology to support learning: pacing, elaboration, confirmation, navigation, and inquiry. The first function is for keeping the progress of the group synchronized. Second, technology may aid elaboration, which develops new information with existing ones. In an online learning context, the provision of feedback to confirm students' comprehension of knowledge can be afforded through programmed computer responses. Next, the implementation of technology may also aid students' ability to navigate interaction with peers and learning content. The last, computer system and the internet are used for inquiry media which provide access to student's interests.

In 1999, Hannafin, Land, and Oliver introduced the foundation, methods, and models of Open-Learning Environment, which significantly impact the development of online learning. The core of Open-Learning Environments reflects educational core values, including psychological, pedagogical, cultural, pragmatics, and technological. Provision of scaffolding is being stressed in the online learning pedagogical aspect. Further, the types, function, and scaffolding method are determined (Hannafin, Land, \& Oliver 1999). To support this, Hannafin et al. (1999), Hill \& Hannafin (2001), Kim \& Hannafin (2011) classify scaffolding based on the source of scaffolding, patterns of interaction between learners and scaffolding providers, and the purpose it serves in online learning.

In line with Vygotsky's notion on the importance of more knowledgeable others to help a learner passing through their ZPD, Scaffolding can be performed either by the teacher or through social interaction with peers. While teachers are mostly seen as the primary source of scaffolding, social interaction and collaboration with peers are also essential to scaffold students' learning. Along with the advancement of technology, Hannafin et al.,(1999) and Kim, Hannafin, \& Bryan (2007) propose the third source of scaffolding: technology. As learning inevitably shift from classroom based into technologybased, the employment of technology to enhance learning is feasible. Recent studies show that the employment of three sources of scaffolding effectively fosters students' achievement in online learning (Bautista, 2013; Hou \& Keng, 2020; Hsiao, Mikolaj, \& Shih, 2017; Kim \& Hannafin, 2011; Kim et al., 2007; Mahan, 2020; Nachowitz, 2018; Sharma \& Hannafin, 2004; Tan, 2018).

As one of the critical components in Vygotsky's Social Development Theory, interaction plays an essential role in scaffolding provision. Referring back to the sources of scaffolding (teacher, peer, and technology), the pattern of interaction between learners, and the source of scaffolds (Kim et al., 2007), scaffolding can be performed through static or dynamic interaction. Kim and Hannafin (2011) describe that static scaffolding does not involve interactions between learners and the source of scaffolding. Static scaffolding helps the learner to navigate the course and getting the resources and tools needed. Examples of static scaffolding include guidelines, procedures, scoring guides, and other tools.

On the other hand, dynamic scaffolding occurs when there is interactive communication between learners and the source of scaffolding. This interaction usually occurs when teachers scaffold students' learning by reviewing students' progress and giving feedback based on students' needs. Teacher and peer feedback, probing questions, hints, and prompts are, to name a few of dynamic scaffolding.

Based on its purpose, Hannafin et al. (1999); Kim \& Hannafin (2011) elaborate on four types of technology-enhanced scaffolding: procedural, conceptual, metacognitive, and strategic scaffolding. Procedural scaffolding is beneficial to help students navigate the online learning environment. Stavredes (2011) elaborates procedural scaffolding into 
orientation, expectation, and resource scaffolding. Orientation at the beginning of the course is critical to foster students' persistence throughout the course. This type of scaffolding describes the key features and tools available in the course, such as a place to access learning material, assignment submission, discussion forum, and others. As the name suggests, expectation scaffolding describes what to expect from the course and what is expected of the students by the end of the course. Effective implementation of procedural scaffolding helps students understand the nature of the course, including how to navigate the learning platforms, how to interact with the teacher, fellow students, and content material. As a result, learning anxiety and frustration can be eliminated (Stavredes, 2011).

In order to help students mastering key concepts being learned, conceptual scaffolding is to be performed (Stavredes, 2011). Through conceptual scaffolding, teachers can check students' comprehension, identify their misconceptions, and clarify those conceptions. An in-depth comprehension of the topic's critical ideas helps students overcome stress and lack motivation in learning.

Beside guiding students with the concept, scaffolding can also be performed by helping students solving problems they faced during learning. It is known as strategic scaffolding (Hannafin et al., 1999). In performing strategic scaffolding, teachers need to adjust the form and amount of support given to the students. In providing scaffolding, there is always a possibility in which students do not receive enough support or otherwise getting it excessively. It reflects the contingency aspect of scaffolding (Van de Pol et al., 2010). The teacher can give alternative explanations and various ways of problem-solving to accommodate students' differentiation.

Online learning and learners' autonomy are two intertwined concepts (Hannafin, Land and Oliver, 1999; Ribbe and Benazilla, 2013; Bautista, 2013). To be an autonomous learner, one has to be able to regulate their own thinking. Thus, metacognition is of importance in online learning context. Metacognitive scaffolding guides student to develop their thinking skills which includes how information is perceived, kept and retrieved. Since the main challenge of online learning environment is direct interaction, online courses must be designed in such a way so that students' metacognition could be well developed. The strategies include helping students to scheme strategies for achieving learning goals (planning), keep track of their progress (monitoring), and assess the progress throughout the course (evaluating).

\section{Scaffolding strategies in synchronous and asynchronous online learning mode}

In general, there are two modes of online learning: synchronous and asynchronous (Bautista, 2013; Dailey-Hebert, 2018; Hannafin et al., 1999). Asynchronous learning, which is the critical component of flexible online learning, is commonly facilitated by media such as Learning Management System (LMS), e-mail, and discussion boards. According to Bautista (2013), asynchronous learning is based on constructivism since it is student-centered. This type of online learning allows learners to log on at any time, download learning materials, ask questions, submit tasks, and give feedback at any convenient time. Thus, students can manage their learning.

On the other hand, synchronous learning is commonly aided by live media such as video conferencing platforms and chat. In contrast with asynchronous learning, this type of learning requires the participant to present at a designated time. The benefit of synchronous learning is the potential support provided by learning communities (teacher and fellow students). Feedbacks and discussions occur more interactively in synchronous mode.

Despite the time flexibility, material accessibility, and availability, the online learning experience still relies significantly on students' autonomy, self-regulation, and participation in the community of inquiry (Bautista, 2013). In order to build up students' autonomy in the two modes of online learning, the four types of scaffolding strategies are applicable since the aim of scaffolding itself is to transfer learning responsibility. Therefore, the following discussion explores how scaffolding is implemented in synchronous and asynchronous learning modes.

Considering the nature of asynchronous learning mode, technology-enhanced scaffolding plays a significant role in fostering students' success in learning. Belland, Kim, \& Hannafin (2013) defines technology-enhanced scaffolding as a "software program that uses such strategies as question prompts, expert/peer modeling, and 
data manipulation tools to augment and improve students' conceptual understanding, metacognition, use of strategies, and understanding of procedures." The ever-presence scaffolds provided with the enhancement of technology are exploited throughout the course to match students' learning pace and accommodate their learning needs.

At the beginning of an online course, procedural scaffolding help students considering how tools and resources are optimally utilized (Hannafin et al., 1999; Hsiao et al., 2017; Stavredes, 2012). Orientation to the course and learning system can be done through posting a tutorial on the system's functions and features (Abdullah, Hussin, Asra, \& Zakaria, 2013; Cacheiro-Gonzalez, Medina-Rivilla, Dominguez-Garrido, \& Medina-Dominguez, 2019; Hsiao et al., 2017; Motte, 2013). Students can always look back at the course roadmap and tutorial whenever they encounter procedural problems throughout the course. Explicit explanations on what to expect from the course and how students are expected to accomplish the course are clarified from the beginning (Stavredes, 2012). The explanation includes class rules, course syllabus, discussion etiquette, and course timeline (Garrison \& Arbaugh, 2007; Hsiao et al., 2017; Stavredes, 2012; ValenciaVallejo, López-Vargas, \& Sanabria-Rodríguez, 2019). Helping students navigate the course roadmap and understand its boundaries is also beneficial for the online instructor to reduce their workload (Hansen and Gray, 2018). Guidance on how and where to access learning resources and other supportive tools should also be clarified at the beginning of the course. Hill \& Hannafin (2001); Martin, Dornfeld Tissenbaum, Gnesdilow, \& Puntambekar (2019); Schutt (2003) suggest that links to these resources should be available and easily accessible in the learning system. Helping students navigate the course roadmap and understand its boundaries is also beneficial for the online instructor to reduce their workload (Hansen and Gray, 2018).

Conceptual scaffolding can be employed to help students mastering key concepts in asynchronous mode. Applying conceptual scaffolding is meant to ensure students' comprehension of the learning material, identify misconceptions, and clarify misconceptions (Hannafin et al., 1999; Stavredes, 2012). Scaffolds can be performed by providing list of terminologies and definition, concept maps, and supplement materials (De Guerrero \& Villamil, 2000; Garrison \& Arbaugh, 2007; Hou \& Keng, 2020; Hsiao et al., 2017; Mahan, 2020; Razaghi, Bagheri, \& Yamini, 2019; Schutt, 2003; Sharma \& Hannafin, 2004). During asynchronous discussion, provision of discussion starters, hints, and probing questions are also proven to be beneficial not only to strengthen students' comprehension but also to check their mastery of a particular concept (Chen \& Tseng, 2019; Mahan, 2020; Nachowitz, 2018; Razaghi et al., 2019; Schutt, 2003; Tan, 2018).

Closely related to conceptual scaffolds, the provision of strategic scaffolding is also of importance. It means adjusting the form and amount of support to accommodate students' diversity, which eventually lead to content and skill mastery. In asynchronous learning mode, strategic scaffolding can be performed through provision of various learning resources and tools, differentiated instruction, and alternative explanation to key concepts (Belland et al., 2017; Hill \& Hannafin, 2001; Hou \& Keng, 2020; Martin et al., 2019; Pentimonti et al., 2017; Schutt, 2003; Sharma \& Hannafin, 2004; van de Pol et al., 2010). Motivating messages can be posted regularly in order to encourage participation and keep students' motivation high (Bautista, 2013; Hsiao et al., 2017; Motte, 2013; Nachowitz, 2018; Ozan, 2013; Schutt, 2003; Tan, 2018).

In taking an asynchronous learning mode, learners should regulate their learning, including managing their thinking processes (metacognition). The provision of metacognitive scaffolding helps students develop their thinking skills, including how information is perceived, kept, and retrieved. The strategies include planning learning goals, monitoring, and evaluating learning progress. In order to plan learning purposes, course overview, timeline, and task completion guidelines are to be posted in the learning system so that students know their learning direction (Mamun, Lawrie, \& Wright, 2020; Razaghi et al., 2019; Sharma \& Hannafin, 2004; Stavredes, 2012; Valencia-Vallejo et al., 2019). The following strategies are suggested for monitoring students' progress: providing templates and worked examples of how tasks should be done (Abdullah et al., 2013; Mahan, 2020; Razaghi et al., 2019), delivering quizzes to check topic mastery regularly (Tan, 2018), and posting a checklist for completed tasks. In order for the students to be able to evaluate their 
learning, scoring rubric with detailed criteria should be posted (Razaghi et al., 2019; Stavredes, 2012) and feedbacks on the task are to be given (Dailey-Hebert, 2018; Ozan, 2013; Razaghi et al., 2019).

In contrast to self-paced asynchronous learning, participants gathered at a specified time in an agreed-upon learning platform in synchronous online learning mode. It allows social interaction and a sense of learning community, which leads to students' engagement to the learning environment. Khan, Egbue, Palkie \& Madden, (2017) stress importance of students' engagement to their success in online learning. Besides, synchronous learning allows scaffolding from the teacher and through peer interaction, primarily through discussions and interactive feedback.

To foster students' autonomy and selfregulation, it is of importance to implement the four types of online scaffolding in synchronous online learning. At the beginning of an online course, procedural scaffolding can be performed by building up students' engagement through interactive communication with the course instructor and peers (Abdullah et al., 2013; Foley \& Marr, 2019; Garrison \& Arbaugh, 2007; Khan et al., 2017). Through synchronized communication teacher can clarify their teaching style and availability (Cacheiro-Gonzalez et al., 2019; Hansen \& Gray, 2018; Stavredes, 2012).

Synchronized discussion can also provide conceptual scaffolding by checking students' comprehension, identifying their misconceptions, and clarifying the misconception. The teacher can ask a probing question, give advice, show hints, or state discussion starters to support students conceptual mastery (Chen \& Tseng, 2019; Kim et al., 2007; Mahan, 2020; Mamun et al., 2020; Peterson, Beymer, \& Putnam, 2018; Schutt, 2003; Stavredes, 2012). As for strategic scaffolding, encouragement to participation through discussion and motivating feedback given to students in need are to be delivered in synchronous mode (Bautista, 2013; Belland et al., 2017; De Guerrero \& Villamil, 2000; Khan et al., 2017; Nachowitz, 2018; Ozan, 2013; Schutt, 2003; Tan, 2018). In order to build up social interaction, the teacher should actively participate throughout the course (Bautista, 2013; Dailey-Hebert, 2018; Kim et al., 2007; Nachowitz, 2018) and encourage peer interaction and collaboration (De Guerrero \& Villamil,
2000; Hanjani, 2019; Hou \& Keng, 2020; Ranjbar \& Ghonsooly, 2017). Finally, fostering metacognition in synchronous mode can be performed through encouraging problem solving and strategic thinking (De Guerrero \& Villamil, 2000; Motte, 2013; Sharma \& Hannafin, 2004; Valencia-Vallejo, López-Vargas, \& SanabriaRodríguez, 2018).

Both in asynchronous and synchronous mode, scaffolding is crucial to foster students' achievement in online learning. Since scaffolding aims to build up students' autonomy, scaffolding is employed chiefly at the beginning of the course. As the course progresses, the amount of support given is reduced. It reflects the fading characteristics of scaffolding. Support provided is adjusted throughout the course to respond to students' learning needs, which implies scaffolding contingency. At last, when students can master the learning concept, make their own learning decision, and regulate their thinking, transfer of responsibility occurs. This emphasizes the importance of scaffolding strategies in the online learning context.

\section{CONCLUSION}

Self-regulation and learning autonomy are critical factors of a successful online course. Thus, it is of importance for online instructors to design a course in such a way so that students can regulate their learning. Integration of scaffolding strategies to help students build up autonomy in learning online. Like face-to-face classrooms, scaffolding given in an online context consists of three aspects: contingency, fading, and transfer of responsibility. The four types of online scaffolding are applicable both in synchronous and asynchronous learning. However, static, technology enhanced-scaffolding is primarily employed in asynchronous learning mode. In synchronous learning mode, support is provided chiefly through dynamic interaction with teachers and peers. The findings of this study imply that scaffolding strategies should be integrated into online learning design. Therefore, further research on the framework for integrating scaffolding strategies in online courses should be conducted.

\section{REFERENCES}

Abdullah, M. R. T. L., Hussin, Z., Asra, \& Zakaria, A. R. (2013). Mlearning scaffolding model for undergraduate English language learning: Bridging formal and informal learning. Turkish 
Online Journal of Educational Technology, 12(2), 217-233.

Abdullah, R. N., Abdul Muait, J., \& Ganefri, G. (2019). Students' perception towards modern technology as teaching Aids. Asian Journal of Assessment in Teaching and Learning, 9(2), 3742.

Albrahim, F. A. (2020). Online Teaching Skills and Competencies. In TOJET: The Turkish Online Journal of Educational Technology (Vol. 19).

Anderson, T., \& Garrison, D. R. (2003). E-Learning in the 21st Century: A Framework for Research and Practice. New York: RoutledgeFalmer.

Aveyard, H. (2010). Doing a Literature Review in Health and Social Care: A Practical Guide (2nd ed.). New York: Open University Press.

Bautista, R. G. (2013). The reciprocal determinism of online scaffolding in sustaining a community of inquiry in physics. Journal of Technology and Science Education, 3(2), 89-97.

Belland, B. R., Kim, C. M., \& Hannafin, M. J. (2013). A Framework for Designing Scaffolds That Improve Motivation and Cognition. Educational Psychologist, 48(4), 243-270.

Belland, B. R., Walker, A. E., Kim, N. J., \& Lefler, M. (2017). Synthesizing Results From Empirical Research on Computer-Based Scaffolding in STEM Education: A Meta-Analysis. Review of Educational Research, 87(2), 309-344.

Cacheiro-Gonzalez, M. L., Medina-Rivilla, A., Dominguez-Garrido, M. C., \& MedinaDominguez, M. (2019). The learning platform in distance higher education: Student's perceptions. Turkish Online Journal of Distance Education, 20(1), 71-95.

Chen, S. Y., \& Tseng, Y. F. (2019). The impacts of scaffolding e-assessment English learning: a cognitive style perspective. Computer Assisted Language Learning, O(0), 1-23.

Dailey-Hebert, A. (2018). Maximizing Interactivity in Online Learning: Moving Beyond Discussion Boards. Journal of Educators Online, 15(3).

De Guerrero, M. C. M., \& Villamil, O. S. (2000). Activating the ZPD: Mutual Scaffolding in L2 Peer Revision. The Modern Language Journal, 84(1), 51-68.

Foley, K., \& Marr, L. (2019). Scaffolding extracurricular online events to support distance learning university students. Journal of Interactive Media in Education, 2019(1), 1-6.

Garrison, D. R., \& Arbaugh, J. B. (2007). Researching the community of inquiry framework: Review, issues, and future directions. Internet and Higher Education, 10(3), 157-172.

George, M. W. (2008). Library research. New Jersey: Princeton University Press.

Hanjani, A. M. (2019). Collective peer scaffolding, self-revision, and writing progress of novice EFL learners. International Journal of English
Studies, 19(1), 41-57.

Hannafin, M., Land, S., \& Oliver, K. (1999). Open learning environments: Foundations, methods, and models. In C. M. Reigeluth (Ed.), Instructional-Design Theories and Models: A New Paradigm of Instructional Theory.

Hansen, B., \& Gray, E. (2018). Creating Boundaries Within the Ubiquitous Online Classroom. Journal of Educators Online, 15(3).

Harasim, L. (2000). Harasim2000. 3, 41-61.

Hill, J. R., \& Hannafin, M. J. (2001). Teaching and learning in digital environments: The resurgence of resource-based learning. Educational Technology Research and Development, 49(3), $37-52$.

Hou, H. T., \& Keng, S. H. (2020). A Dual-Scaffolding Framework Integrating Peer-Scaffolding and Cognitive-Scaffolding for an Augmented Reality-Based Educational Board Game: An Analysis of Learners' Collective Flow State and Collaborative Learning Behavioral Patterns. Journal of Educational Computing Research.

Hsiao, E. L., Mikolaj, P., \& Shih, Y. T. (2017). A design case of Scaffolding hybrid/online studentcentered learning with multimedia. Journal of Educators Online, 14(1).

Khan, A., Egbue, O., Palkie, B., \& Madden, J. (2017). Active learning: Engaging students to maximize learning in an online course. Electronic Journal of E-Learning, 15(2), 107-115.

Kim, M. C., \& Hannafin, M. J. (2011). Scaffolding problem solving in technology-enhanced learning environments (TELEs): Bridging research and theory with practice. Computers and Education, 56(2), 403-417.

Kim, M. C., Hannafin, M. J., \& Bryan, L. A. (2007). Technology-Enhanced Inquiry Tools in Science Education: An Emerging Pedagogical Framework for Classroom Practice. Science Education, 91(6), 1010-1030.

Mahan, K. R. (2020). The comprehending teacher: Scaffolding in content and language integrated learning (CLIL). Language Learning Journal, $0(0), 1-15$.

Mamun, M. A. Al, Lawrie, G., \& Wright, T. (2020). Instructional design of scaffolded online learning modules for self-directed and inquiry-based learning environments. Computers and Education, 144(December 2018), 103695.

Martin, N. D., Dornfeld Tissenbaum, C., Gnesdilow, D., \& Puntambekar, S. (2019). Fading distributed scaffolds: the importance of complementarity between teacher and material scaffolds. Instructional Science, 47(1), 69-98.

Motte, K. (2013). Strategies for online educators. Turkish Online Journal of Distance Education, 14(2), 258-267.

Nachowitz, M. (2018). Scaffolding progressive online discourse for literary knowledge building. 
Online Learning Journal, 22(3), 133-156.

Ozan, O. (2013). Scaffolding in Connectivist. Turkish Online Journal of Distance Education, 14(2), 44-55.

Pentimonti, J. M., Justice, L. M., YeomansMaldonado, G., McGinty, A. S., Slocum, L., \& O'Connell, A. (2017). Teachers' Use of Highand Low-Support Scaffolding Strategies to Differentiate Language Instruction in HighRisk/Economically Disadvantaged Settings. Journal of Early Intervention, 39(2), 125-146.

Peterson, A. T., Beymer, P. N., \& Putnam, R. T. (2018). Synchronous and asynchronous discussions: Effects on cooperation, belonging, and affect. Online Learning Journal, 22(4), $7-$ 25.

Ranjbar, N., \& Ghonsooly, B. (2017). Peer scaffolding behaviors emerging in revising a written task: A microgenetic analysis. Iranian Journal of Language Teaching Research, 5(2), 75-90.

Razaghi, M., Bagheri, M. S., \& Yamini, M. (2019). The impact of cognitive Scaffolding on Iranian EFL learners' speaking skill. International Journal of Instruction, 12(4), 95-112.

Ribbe, E., \& Bezanilla, M. J. (2013). Scaffolding learner autonomy in online university courses El desarrollo de la autonomía del estudiante en los cursos online universitarios. Digital Education Review, (24), 98-113.

Schutt, M. (2003). Scaffolding for Online Learning Environments: Instructional Design Strategies that Provide Online Learner Support. Educational Technology, 43(6), 28-35.

Sharma, P., \& Hannafin, M. (2004). Scaffolding critical thinking in an online course: An exploratory study. Journal of Educational Computing Research, 31(2), 181-208.

Stavredes, T. (2012). Effective Online Teaching:
Foundations and Strategies for Student Success. San Francisco: Jossey-Bass.

STOUT, G. F. (1891). Ii-Thought and Language. Mind, pp. 181-205.

Tan, Y. L. L. (2018). Meaningful gamification and students' motivation: A strategy for scaffolding reading material. Online Learning Journal, 22(2), 141-156.

Todo, M. F. L., \& Budiarta, I. W. (2018). Critical Discourse Analysis on Kompas Daily Newspaper Report on Profiteering through the Names of President Jokowi and Vice President Jusuf Kalla. RETORIKA: Jurnal Ilmu Bahasa, 4(1).

Valencia-Vallejo, N., López-Vargas, O., \& SanabriaRodríguez, L. (2018). Effect of motivational Scaffolding on e-learning environments: Selfefficacy, learning achievement, and cognitive style. Journal of Educators Online, 15(1).

Valencia-Vallejo, N., López-Vargas, O., \& SanabriaRodríguez, L. (2019). Effect of a metacognitive scaffolding on self-efficacy, metacognition, and achievement in e-learning environments. Knowledge Management and E-Learning, 11(1), $1-19$.

Van de Pol, J., Volman, M., \& Beishuizen, J. (2010). Scaffolding in teacher-student interaction: A decade of research. Educational Psychology Review, 22(3), 271-296.

Vygotsky, L. (1978). Mind in Society: The Development of Higher Psychological Processes (M. Cole, V. John-Steiner, S. Scribner, \& E. Souberman, Eds.). Cambridge: Harvard University Press.

Wood, D., Bruner, J. S., \& Ross, G. (1976). the Role of Tutoring in Problem Solving. Journal of Child Psychology and Psychiatry, 17(2), 89-100. 